\title{
MEMAHAMI PERAN YESUS DAN ROH KUDUS DALAM INJIL LUKAS DENGAN BINGKAI PEMIKIRAN PIERRE FELIX BOURDIEU
}

\author{
Krueger Kristanto Tumiwa \\ Fakultas Teologi, IAKN Manado \\ kruegertumiwa@iakn-manado.ac.id \\ Diterima 1 Februari 2019 \\ Disetujui 13 Maret 2019
}

\begin{abstract}
This article aims to understand the role of the Holy Spirit and Jesus in Luke's Gospel using an interpretive approach that utilizes social science. This way of understanding is called an effort to understand the text using a social approach (utilizing social sciences). This article uses descriptive analysis method by describing research results from various primary and secondary literature sources related to the topic. The Holy Spirit in Luke's Gospel has an important role in work of Jesus' ministry. The writer of the Gospel of Luke does pay special attention to the Holy Spirit in his writings. This article wants to examine how the position or role of the Holy Spirit and Jesus themselves in social practice uses the thoughts of Pierre Felix Bourdieu. Some important things from Bourdieu such as habitus, agency, capital, and social practice become the emphasis in this article.
\end{abstract}

Keywords: Jesus, Holy Spirit, Luke's Gospel, Bourdieu

ABSTRAK

Artikel ini bertujuan untuk memahami peran Roh Kudus dan Yesus dalam Injil Lukas menggunakan pendekatan tafsir yang memanfaatkan ilmu sosial. Cara memahami ini disebut dengan upaya memahami teks dengan menggunakan pendekatan sosial (memanfaatkan ilmu-ilmu sosial).Artikel ini menggunakan metode analisisdeskriptif dengan menguraikan hasil penelitian dari berbagai sumber literature primer maupun sekunder terkait topik.Roh Kudus dalam Injil Lukas memiliki peran penting dalam pekerjaan pelayanan Yesus. Penulis Injil Lukas memang menaruh perhatian khusus terhadap Roh Kudus dalam tulisannya. Artikel ini ingin memeriksa bagaimana posisi atau peran Roh Kudus dan Yesus itu sendiri dalam praktik sosial menggunakan pemikiran dari Pierre Felix Bourdieu. Beberapa hal penting dari Bourdieu seperti habitus, agensi, modal, dan praktik sosial menjadi penekanan dalam artikel ini.

Kata Kunci: Yesus, Roh Kudus, Injil Lukas, Bourdieu

\section{PENDAHULUAN}

Agama Kristen yang dalam hal ini adalah gereja dalam sejarahnya telah mengalami pertumbuhan dan perkembangan yang sangat pesat. Meskipun demikian dalam pertumbuhan dan perkembangannya yang sangat pesat itu, gereja juga mengalami begitu banyak tantangan. Dalam pertumbuhan dan perkembangannya itu, baik para rasul maupun para misionaris yang menyebarluaskan kekristenan di dunia ini, tak lepas dari karya Roh Kudus. Roh Kudus dipercaya memiliki peran penting dalam kehidupan orang percaya. Sama seperti dalam kehidupan Yesus, Roh Kudus 
berperan penting dalam Misi Pembebasan yang dikerjakan Yesus; menyampaikan kabar baik kepada orang-orang miskin, membebaskan orang-orang yang tertawan, memberikan penglihatan bagi orang-orang buta, membebaskan orang-orang yang tertindas, dan memberitakan tahun rahmat Tuhan telah datang (Luk. 4:18-19).

Hingga kini ada banyak pemahaman tentang Roh Kudus dari berbagai aliran gereja. Bahkan topik tentang Roh Kudus menjadi perdebatan hangat di antara aliran-aliran gereja dan para teolog. Oleh karena itu dalam penelitian ini penulis tertarik untuk meneliti tentang Roh Kudus. Penulis tertarik sebab pembahasan dan permasalahan Roh Kudus itu sudah bertahun-tahun dibicarakan bahkan sampai sekarang. Seperti yang sudah dikatakan di atas, Roh Kudus dipercaya memiliki peran penting dalam pertumbuhan dan perkembangan kekristenan, bahkan sebelum kekristenan ada, Roh Kudus sudah banyak berkarya seperti yang diceritakan dalam Alkitab. Namun, penulis hanya akan meneliti Roh Kudus dalam Injil Lukas. Alasan penulis memilih Injil Lukas sebab Injil Lukas adalah Injil yang cukup memberi perhatian kepada Roh Kudus itu sendiri. Hal menarik

\footnotetext{
${ }^{1}$ Daniel Sutoyo, "Pneumatologi Lukas: Pemberdayaan Pelayanan Kristen" dalam Antusias: Jurnal Teologi dan Pelayanan, Vol. 4, 2015.
}

dalam tulisan Lukas tentang Roh Kudus yaitu Roh Kudus berperan penting dalam karya Allah atas umat manusia.

Dewasa ini, ada banyak diskursus mengenai Yesus dan Roh Kudus khususnya dalam Injil Lukas.Beberapa di antaranya yaitu, artikel dari Daniel Sutoyo yang menekankan pada konsep tentang Roh Kudus dalam Injil Lukas dan juga Kisah Para Rasul dalam hubungannya dengan pemberdayaan pelayanan Kristen dari waktu ke waktu. ${ }^{1}$ Artikel ini bernuansa yang mirip dengan Diserta yang ditulis oleh Justin Thorpe Mason. Mason mengemukakan bahwa Roh Kudus memiliki peran yang besar dalam membimbing atau memimpin gereja. Konsep mengenai Roh Kudus juga ditelusuri dari Injil Lukas dan Kisah Para Rasul. Dalam kesimpulannya, Mason menekankan bahwa sejak masa gereja mula-mula hingga kini peran Roh Kudus begitu penting dalam memimpin, memerintah dan menjaga gereja dalam mewujudkan tujuan Allah yaitu Kerajaan Allah itu sendiri. ${ }^{2}$ Artikel lain dari Frank D. Macchia menekankan pada konsep Roh Kudus dengan pertobatan. Penelitian Macchia bersumber dari frasa “... membaptis kamu dengan Roh Kudus dan

${ }^{2}$ Justin Thorpe Mason, The Role of the Holy Spirit in Leading Ecclesial Change in Luke-Acts, disertasi pada The Southern Baptist Theological Seminary, Desember 2015. 
dengan api" (Lukas 3:16). Macchia menekankan pada pentingnya memerhatikan teologi penebusan dosa dengan Roh Kudus yang ditandai dengan penyaliban Yesus. $^{3}$

Berbeda dari penelitian-penelitian sebelumnya yang mendiskusikan topik tentang Roh Kudus dalam Injil Lukas, artikel ini membahas tentang Yesus dan Roh Kudus dalam kerangka berpikir Pierre Felix Bourdieu. Artikel ini tidak secara spesifik membahas tentang konsep Roh Kudus tetapi memahami dari sudut pandang Bourdieu bagaimana posisi Roh Kudus atau peran Roh Kudus dalam praktik sosial Yesus. Yesus dipahami tidak lepas dari ruang sosialnya.

\section{METODE PENELITIAN}

Metode yang dipakai merupakan pengembangan dari metode tafsir tradisional, seperti metode historis-kritis yang banyak digunakan dalam kerja tafsir Alkitab. Teks Alkitab tidak bisa dilepaskan dari aspek sosial, antropologi, dan budaya sebab segala peristiwa yang tertulis dalam Alkitab berangkat dari konteks masyarakat tertentu. Oleh karena itu, upaya memahami teks Alkitab dari perspektif sosiologis sangat dimungkinkan. Seperti yang

${ }^{3}$ Frank D. Macchia, "Baptism in the Holy Spirit-and-Fire: Luke's Implicitly Pneumatological Theory of Atonement, dalam Jurnal Religions, 9, 63, 2018. dikemukakan oleh Yusak Tridarmanto bahwa dalam hal ini teks Alkitab akan dibaca dengan tetap memerhatikan konteks sosial atau setting sosialnya (sitz im leben). Konteks sosial itu jika dikaji dan dihubungkan dengan cerita dalam Alkitab maka akan melahirkan suatu makna. ${ }^{4}$ Ilmu sosial yang dimaksud dalam hal ini yaitu pemikiran dari Pierre Felix Bourdieu tentang habitus, ranah, modal, dan aktor/agensi. Pokok-pokok pikiran dari Bourdieu itu akan disinggung dalam pembahasan/diskusi yang dikaitkan dengan posisi Yesus dan Roh Kudus di tengah realitas sosial. Artikel ini akan diuraikan secara deskriptif-analitis dengan menggunakan sumber-sumber literatur, baik primer maupun sekunder.

\section{HASIL DAN PEMBAHASAN}

\section{Yesus, Habitus, dan Agensi}

Dalam Injil-Injil, atau bisa dikatakan dalam keseluruhan kitab Perjanjian Baru, Yesus merupakan tokoh sentral dalam penceritaan. Secara khusus dalam Injil Lukas ketokohan Yesus itu sudah mulai dinampakkan pada bagian awal kitab. Sebagai tokoh sentral, keberadaan Yesus dalam cerita - secara khusus dalam Injil Lukas - harus tetap

4 Yusak Tridarmanto, Hermeneutika Perjanjian Baru 1, (Yogyakarta: Kanisius, 2013), h. 37. 
dimengerti dengan memerhatikan aspek sosialnya. Sebab Yesus lahir di tengah masyarakat yang sudah memiliki tatanan sosial tertentu. Jika Yesus dimengerti tanpa memerhatikan konteks sosialnya maka akan sangat sulit menjawab pertanyaan "kenapa Yesus memulai pekerjaan-Nya saat Ia berumur kira-kira tiga puluh tahun? Kenapa tidak lebih awal?"

Yesus tidak bisa dipahami tanpa konteks sosialnya karena pada dasarnya Ia hidup dalam suatu tatanan sosial. Dalam pemikiran Bourdieu, Yesus hidup dalam suatu habitus tertentu. Habitus dalam pengertian sederhananya merupakan suatu tatanan hidup yang dijalani sebagai hasil produksi dari sejarah, peristiwa, budaya yang sudah lama berlangsung dalam komunitas atau masyarakat. ${ }^{5}$ Dalam hal ini Yesus hidup dalam habitus hasil dari mekanisme masyarakat Romawi (bahkan juga dipengaruhi oleh Babilonia dan Makedonia) yang mengatur berbagai tatanan sosial yang tidak mungkin didobrak begitu saja. Sebagai bagian yang tidak terpisahkan dari struktur sosial/masyarakat, Yesus diperhadapkan dengan praktik internalisasi-eksternalitas dan eksternalisasi-internalitas. ${ }^{6}$ Artinya, Yesus dalam praktik hidup kesehariannya sedikit-

${ }^{5}$ Pierre Bourdieu, Outline of a Theory of Practice, (London: Cambridge University Press, 1977), p. 82. banyak dipengaruhi oleh kondisi-kondisi sosial yang sudah ada. Misalnya, bagaimana bersikap di tengah komunitas, gaya berbahasa, gaya berpakaian, atau cara memandang situasi tertentu. Jadi hal-hal yang sebenarnya berasal dari luar diri Yesus "diadaptasikan" oleh Yesus (proses internalisasi-eksternalitas). Tapi bukan berarti Yesus hanya menjadi individu yang pasif. Dalam prosesnya, Yesus juga memiliki struktur atau "keinginan" subjektif-Nya sendiri yang memungkinkan Dia memengaruhi atau melakukan agensi terhadap struktur objektif atau tatanan masyarakat-Nya (proses eksternalisasiinternalitas).

Kisah Yesus yang memutuskan tinggal di Yerusalem dan berdiskusi dengan para alim ulama di Bait Allah (Lukas 2:4152) merupakan salah satu contoh proses eksternalisasi-internalitas dari Yesus. Ada efek dari keputusan Yesus itu, yaitu para alim ulama itu merasa heran atau tercengang dengan kecerdasan dan tanggapan Yesus. Tidak diketahui secara pasti topik apa yang didiskusikan Yesus dengan para alim ulama tapi paling tidak dari ekspresi keheranan mereka Yesus sudah berhasil meninggalkan kesan (atau bahkan ideologi) dalam benak mereka.

${ }^{6}$ Kukuh Yudha Karnanta, "Paradigma Teori Arena Produksi Kultural Sastra: Kajian Terhadap Pemikiran Pierre Bourdieu" dalam Jurnal Poetika, Vol. 1 No. 1, Juli 2013, h. 9-10. 
Yesus, sebagai individu atau agen dalam pemikiran Bourdieu, berhasil memengaruhi struktur objektif-Nya. Meski demikian, perlu disadari bahwa dalam proses internalisasi-eksternalitas itu diperlukan bekal yang memungkinkan Yesus memengaruhi struktur objektif-Nya.

\section{Kuasa Roh Kudus sebagai Modal}

Dalam suatu komunitas atau masyarakat, proses eksternalisasiinternalitas dan internalisasi-eksternalitas tidak hanya dilakukan oleh agen tunggal tapi oleh seluruh anggota komunitas. Dalam kisah Yesus, bukan hanya Yesus sendiri yang melakukan proses itu tetapi ada juga individu yang lain. Yesus hadir dalam ruang sosial (ranah, arena / field) yang memiliki banyak individu yang berkontestasi dalam perebutan posisi atau penyebaran kekuasaan. Yesus sendiri pun dalam usaha penyebaran paradigma pemerintahan Kerajaan Allah diperhadapkan dengan banyak lawan. Dalam Injil Lukas bisa ditemukan para lawan Yesus, mulai dari orang-orang Farisi, Ahli Taurat, Saduki, hingga kekaisaran Romawi. Dalam kontestasi ini diperlukan modal yang memungkinkan efektif dalam persaingan. ${ }^{7}$ Bourdieu menyebut beberapa

${ }^{7}$ Pierre Bourdieu, The Rules of Art, (California: Standford University Press, 1996), p. 114.

${ }^{8}$ Pierre Bourdieu, The Form of Capital, dalam J.G. Richardson (ed) Handbook of Theory hal yang bisa dikategorikan sebagai modal seperti modal ekonomi, pengetahuan, jaringan sosial, status, atau otoritas yang dianggap sebagai modal simbolik. ${ }^{8}$

Menariknya dalam persaingan itu, memiliki keseluruhan modal itu tidak secara otomatis memenangkan kontestasi. Meskipun semakin banyak modal yang dimiliki maka semakin tinggi hirarki dan diferensiasi seorang agen dalam ruang sosial. ${ }^{9}$ Dalam hal ini, Yesus pada awal pelayanan-Nya tidak memiliki semua modal itu. Tetapi Ia memiliki modal yang sangat dibutuhkan oleh ruang sosial saat itu.Ruang sosial Yesus yang merupakan arena atau ranah merupakan ruang sosial yang diisi oleh masyarakat Yahudi secara umum yang sudah merasakan penderitaan akibat penjajahan dari banyak bangsa, termasuk dari kekaisaran Romawi saat itu. Orang-orang Yahudi menanti-nantikan datangnya pembebasan sesuai dengan nubuatan para Nabi terdahulu. Yesus hadir di tengah ruang sosial dengan modal yang dibutuhkan oleh ruang sosial itu.

Deklarasi Yesus tentang kabar baik dan pembebasan (Lukas 4:18-19) disampaikan kepada banyak orang saat itu dengan dasar bahwa Roh Tuhan ada padaNya. Bagian ayat ini merupakan ayat

and Research for the Sociology of Education, New York: Greenwood Press, 1986), pp. 243-248.

${ }^{9}$ Haryatmoko, Membongkar Rezim Kepastian: Pemikiran Kritis Post-Strukturalis, (Yogyakarta: Kanisius, 2016), h. 45-47. 
nubuatan nabi Yesaya (bdk. Yesaya 61:12). Secara historis, nabi Yesaya (dalam Yesaya 61) benubuat tentang keselamatan yang akan datang kepada bangsa Israel yang pada saat itu sedang dalam masa pembuangan. Kabar selamat itu bersifat eksklusif sebab hanya ditujukan kepada bangsa Israel; hari pembalasan Allah akan tiba (Yesaya 61:2), orang-orang luar atau orang-orang asing akan melayani bangsa Israel (Yesaya 61:5), Israel akan menikmati kekayaan bangsa-bangsa lain (Yesaya 61:6), dst.

Berbeda dengan Injil-injil Sinoptik lainnya, bagian bacaan ini ditempatkan oleh Lukas dibagian awal tulisannya. Dalam Injil Markus dan Matius, bagian bacaan ini ditempatkan jauh setelah Yesus melakukan pelayanan-Nya (bdk. Markus. 6:1-6; Matius. 13:53-58). Sedangkan Lukas, menempatkan bagian bacaan ini tepat setelah cerita tentang pencobaan di padang gurun. Ini mengidikasikan bahwa Lukas ingin menempatkan perikop ini guna memperkuat teologi dalam tulisannya dalam memenuhi tujuan penulisannya yaitu memberikan semangat kepada jemaat yang menanti kedatangan Sang Mesias.

Dikisahkan dalam perikop ini Yesus membaca bagian dari kitab Yesaya (Yesaya

${ }^{10}$ Donald Guthrie, Teologi Perjanjian Baru 2: Misi Kristus, Roh Kudus, Kehidupan Kristen, (Jakarta: BPK Gunung Mulia, 2011), h. 150.
61:1-2) dan menegaskannya dengan: "Pada hari ini genaplah nas ini sewaktu kamu mendengarnya" (Lukas 4:21). Tentunya hal ini membuat yang mendengarnya merasa sangat senang sebab sekian waktu lamanya mereka menunggu, akhirnya keselamatan/tahun rahmat Tuhan itu datang kepada mereka; kerajaan Israel akan pulih dan tidak ada lagi penjajahan. Seperti yang dikemukakan oleh Donald Guthrie ${ }^{10}$, nats Yesaya itu menggambarkan jenis pelayanan yang akan dijalankan Yesus sebagai peberita kabar baik, menyembuhkan dan membebaskan. Sekali lagi menurutnya, bahwa penekanan sifat mesianis terlihat dalam pengurapan Orang yang memiliki Roh itu, yang dinubutkan dalam nats tersebut.

Bagi Robert J. Karris ${ }^{11}$, Lukas mengangkat tema ini untuk menunjukkan inilah cara keramahan Allah yang 'tersenyum' kepada semua orang dalam diri Yesus yang memberitakan dan menyembuhkan. Yesus digambarkan sebagai teman bagi orang-orang berdosa dan orang-orang terpinggirkan, makan dengan mereka, mengabarkan kabar baik bagi orang-orang miskin dan tertindas. Dengan demikian, Yesus adalah penyataan kebaikan Allah bagi manusia.

${ }^{11}$ Robert J. Karris, Invitation To Luke: A Commentary on the Gospel of Luke with Complete Text from The Jerusalem Bible, (New York: Image Books, 1977), pp. 57-58 
Pada Lukas 4:18, kalimat Roh Tuhan ada pada-Ku jika dilihat pada naskah Yunaninya tertulis pneuma küriou ep' eme. Jika diteliti, kata depan ep' dari kata epi (jika diikuti dengan kasus akusatif) maka berarti "atas..." atau dalam KJV diterjemahkan The Spirit of the Lord is upon me. Menujukkan bahwa bukan Yesus yang mengendalikan kuasa itu melainkan kuasa Allah itulah yang menguasai Yesus dengan cara menaunginya (berada di atasNya). Dengan demikian, kerja selamat yang akan dilakukan Yesus, seperti yang dinubuatkan oleh nabi Yesaya, adalah kerja selamat yang disertai dengan peran serta kuasa Allah dalam hidup-Nya.

Singkatnya, kuasa Allah yang berkarya melalui Yesus itu adalah kuasa Allah yang berperan membawa misi pembebasan bagi umat. Melalui Yesus kuasa Allah membebaskan orang-orang yang tertawan, melepasakan umat dari belengggu-belenggu kesengsaraan termasuk kemiskinan, sakit-penyakit dan penindasan. Inilah modal yang dimiliki Yesus dalam ranah persaingan itu. Modal yang memungkinkan Yesus menjawab kebutuhan dari ruang social yang menjadi arena atau ranah bagi Yesus dalam menyebarkan kedaulatan atau pemerintahan Allah.

\section{2, h. 148}

Deklarasi bahwa Roh Tuhan ada pada Yesus tidak muncul begitu saja. Pernyataan ini berdasar pada peristiwa sesudah pembaptisan Yesus: “dan turunlah Roh Kudus dalam rupa burung merpati ke atas-Nya. Dan terdengar suara dari langit: "Engkaulah Anak-Ku yang Kukasihi, kepada-Mulah Aku berkenan” (Lukas 3:22).Pada bagian bacaan ini terdapat perbedaan mencolok ketika Ia dibaptis. Dalam Injil Lukas, ia mengatakan bahwa ketika Yesus sedang dibaptis dan sedang berdoa... Kata berdoa tidak ditemukan dalam kedua Injil Sinoptik lainnya. Ini adalah ciri khas Lukas yang selalu menggambarkan Yesus yang begitu dekat dengan Bapa-Nya. Kegiatan tersebut selalu dilakukan Yesus sebelum Ia memulai pelayanan-Nya (Luk. 6:12; 9:18; 11:1; dsb.).

Pada ayat 22 dikatakan bahwa Roh Kudus turun ke atas Yesus yang disimbolkan dengan burung merpati. Seperti yang diungkapkan Donald Guthrie $^{12}$ :

Di lingkungan Yahudi terdapat kesejajaran yang berisi kiasan-kiasan tentang Roh dalam wujud merpati yang melayang-layang di atas permukaan air. Hubungan yang erat antara Roh dan merpati, walaupun bukan merupakan bahasa simbol yang khas, menyarankan jenis hubungan yang sama seperti pada baptisan Yesus. Walaupun semua Injil Sinoptik menggambarkan turunnya Roh Kudus 
dalam rupa seekor merpati, namum mereka tidak mempersamakan Roh dengan merpati itu. Lukaslah yang paling jelas berkata bahwa turunnya Roh itu "dalam rupa burung merpati".

Apa yang dikatakan Donald Guthrie bisa dikatakan ada benarnya. Jika dilihat gaya penulis Lukas yang menyusun rapi kitabnya dan menguasai dengan baik Perjajian Lama, maka perlambangan burung merpati dengan Roh 'diadopsi' oleh Lukas dari kisah penciptaan di mana Roh Allah melayang-layang di atas permukaan air (Kej. 1:1). Roh Allah yang melayanglayang di atas air itu yang nantinya berperan dalam karya penciptaan (lih. Hal. 8).

Dalam ayat ini juga dikatakan bahwa Roh Kudus yang dalam rupa burung merpati itu turun ke atas Yesus. Peran Roh Kudus di sini sama seperti yang terjadi pada Maria, yaitu Roh Kudus turun ke atasnya dan menaunginya. Hal ini juga mau menunjukkan bahwa Yesus juga berada dalam naungan kuasa Allah.

Dalam hal ini dapat dikatakan bahwa alasan utama bagi turun-Nya Roh Kudus atas Yesus agar Ia dapat membaptis orang dengan Roh, seperti yang sudah dinubuatkan oleh Yohanes Pembaptis. Dengan kata lain, misi Yesus bukan hanya sekadar bermula dengan Roh, maupun juga

\section{2, h. 148}

diarahkan oleh Roh, yang adalah kuasa Allah itu sendiri ${ }^{13}$.

Peran kuasa Roh dari Tuhan atau Roh Kudus sebagai modal Yesus juga terlihat pada peristiwa di padang gurun: "Yesus, yang penuh dengan Roh Kudus, kembali dari sungai Yordan, lalu dibawa oleh Roh Kudus ke padang gurun" (Lukas 4:1). Dari segi perbandingan sinoptik terdapat perbedaan dalam teks tersebut. Perbedaan itu terdapat pada kata memimpin dalam Markus 1:12. Segera sesudah itu Roh memimpin Dia ke padang gurun. Dalam Lukas 4:1 dan Matius 4:1, keduanya menggunakan kata dibawa. Jika dilihat dari naskah Yunani, kata yang digunakan dalam Injil Markus adalah ekballei dari kata ekballoyang artinya mengusir. Dalam terjemahan New International Version (NIV) kata itu diterjemahkan sent out (dibawa keluar). Dalam Injil Matius, kata yang digunakan menurut naskah Yunaninya adalah anēchthēyang artinya membimbing. Dalam Injil Lukas, kata yang digunakan adalahhēgeto(kata kerja imperfek pasif indikatif dari kata agó)yang artinya dibimbing/dipimpin/dibawa. Kedua kata di atas yakni anēchthēdan hēgetoditerjemahkan dalam NIV dengan led $($ lead $=$ dipimpin/dibimbing $)$. 
Pada bagian ayat 1a dikatakan: Yesus, yang penuh dengan Roh Kudus..., jika dilihat dalam naskah Yunanyinya, ayat tersebut berbunyi demikian: Iésous de plèrēs Pneumatos Hagiou. Kalimat itu jika diterjemahkan secara harfiah maka terjemahannya adalah "Lalu Yesus yang dipenuhi oleh Roh Kudus kembali dari Sungai Yordan itu dan dipimpin oleh Roh ke dalam padang gurun itu”. Jadi, yang dimaksud dengan Yesus yang penuh dengan Roh Kudus adalah Yesus yang dipenuhi (secara sempurna) dengan kuasa dari Roh Kudus, yang dalam hal ini adalah Bapa itu sendiri. Kesempurnaan dalam kuasa Roh Kudus ini diterima Yesus ketika ia memberi diri untuk dibaptis. Selanjutnya, dengan kepenuhan atau kesempurnaan dalam kuasa Roh Kudus ini, maka pencobaan juga merupakan keharusan bagi Yesus yang merupakan persiapan bagi-Nya dalam menjalankan misi-Nya nanti.

Ada pendapat yang mengatakan bahwa pencobaan di padang gurun adalah pencobaan yang dilakukan untuk menguji status Yesus sebagai Anak Allah. O.C. Edward Jr. misalnya mengatakan ${ }^{14}$ :

"Kita akan lebih jelas memahami cerita tiga tahapan Yesus itu kalau kita bertolak dari identitas Yesus sebagai Anak Allah. Identitas tersebut telah ditetapkan baik dalam cerita tentang baptisan maupun

${ }^{14}$ Edwards, O.C. Jr., Injil Lukas Sebagai Cerita: Berkenalan dengan Narasi Salah Satu Injil, (Jakarta: BPK Gunung Mulia, 2009), h. 24 dalam silsilahnya. Dua pencobaan itu dimulai dengan ungkapan "Jika Engkau Anak Allah..." Pokok permasalahan di sini adalah apa arti menjadi Anak Allah bagi Yesus. Sebagian jawabnya adalah bahwa Yesus "penuh dengan Roh Kudus" dan "dibawa oleh Roh Kudus" (Luk. 4:1). Dengan tidak menyerah kepada kehendak setan Yesus menunjukkan bahwa Ia adalah Anak Allah yang dipenuhi oleh Roh Kudus."

Pendapat tersebut ada benarnya jika melihat status Yesus sebagai Anak Allah. Namun yang lebih penting dari itu ialah peran atau karya Roh dalam pencobaan itu. Ketika Yesus dicobai oleh iblis, Roh Kudus berkarya pada Yesus. Dengan kuasa yang menaunginya, Yesus memiliki kemampuan untuk menahan segala ujian dan tawaran dari iblis. Dalam keadaan lapar, iblis mencoba menguji Yesus dengan menyuruh-Nya mengubah batu menjadi roti. Tetapi Yesus menjawab bahwa manusia hidup bukan dari roti saja (Lukas. 4:4). Dalam Injil Matius ditambahkan kalimat "tetapi dari setiap firman yang keluar dari mulut Allah" (Matius 4:4). Bagian ayat ini memiliki kesejajaran dengan Ulangan 8:3, di mana bagian tersebut menceritakan tentang kemurahan Tuhan yang telah membimbing bangsa Israel di padang gurun selama 40 tahun. Dalam hal ini, Yesus mau menunjukkan 
bahwa kehidupan manusia bergantung pada pemeliharaan Allah. Bangsa Israel bisa berjalan di padang gurun selama 40 tahun lamanya karena pemeliharaan Tuhan dalam kehidupan mereka. Dengan demikian, kuasa Allah memampukan Yesus sehingga Ia tetap bertahan dan menyerahkan kehidupan-Nya dalam pemeliharaan Tuhan walau dalam keadaan yang sulit sekalipun.

Kemudian iblis menawarkan kepada Yesus segala yang ada di dunia ini akan diberikan jika Yesus mau menyembahnya. Tetapi Yesus menjawab bahwa hanya Tuhan, Allahlah yang harus disembah dan hanya kepada Dialah manusia berbakti (Lukas 4:5-8). Bagian ini juga sejajar dengan Ulangan 6:13. Dalam bagian tersebut, berisi tentang pengakuan bangsa Israel tentang kepada siapa mereka harus berbakti dan kepada siapa yang patut disembah dan dimuliakan. Bangsa Israel harus menyembah kepada Tuhan, Allah yang membebaskan mereka dari tanah perbudakan di Mesir dan yang menyertai mereka ke tanah yang dijanjikan, tanah Kanaan. Dalam hal ini, dengan kuasa Allah, Yesus menegaskan untuk tidak menghianati Tuhan demi kepuasan nafsu dunia yang ada sebab dari pada-Nyalah semuanya berasal. Sebab jika terjadi demikian maka murka Tuhan akan terjadi

${ }^{15}$ Fitzmyer, J.A., The Gospel According to Luke (I-IX): Introduction, Translation, and Notes, (New York: Doubleday \& Company, 1981), p. 517. dalam kehidupan manusia (Ulangan 6:1415).

Selanjutnya, iblis membawa Yesus ke bubungan Baik Allah dan mencobai Yesus dengan menyuruh Yesus untuk menjatuhkan diri dari bubungan itu agar para malaikat dapat menolong dan mengangkat-Nya. Tetapi sekali lagi Yesus menolak permintaan iblis itu dengan berkata "Jangan kau mencobai Tuhan, Allahmu!" (Lukas 4:9-12). Bagian ini juga dikatakan oleh para ahli sebagai ujian pembuktian bahwa Yesus adalah Anak Allah. Tetapi bagi Fitzmyer hal itu hanyalah sebuah kekonyolan. Yesus menolak untuk memanfaatkankekuasaanNyasebagai

Anakuntuk kepentingantantanganbodohdemi

keselamatanpribadi-Nya. Malahan Yesus memperingatkan iblis terhadap resikomencobai Allah. ${ }^{15}$ Mencobai Allah dalam hal ini adalah meragukan kuasa Allah. Sama seperti yang dilakukan oleh bangsa Israel kepada Musa di Masa. Di mana saat itu mereka kehausan ketika berjalan di padang gurun dan bertengkar dengan Musa untuk meminta air, seolaholah mereka meragukan kuasa Allah yang telah membebaskan mereka dari Mesir. Dengan demikian, dalam hal ini Yesus mau menegaskan untuk tidak meragukan kuasa 
Allah yang berkarya melalui diri-Nya. Roh

Kudus memberikan keberanian kepada Yesus untuk menyatakan bahwa tidak ada seorangpun yang dapat meragukan kuasa Allah untuk berkarya di dalam dunia ini.

Dengan naungan kuasa Allah maka Yesus dimampukan sehingga Ia tetap bertahan dan menyerahkan kehidupan-Nya dalam pemeliharaan Tuhan walau dalam keadaan yang sulit sekalipun. Diberikan kemampuan untuk menegaskan bahwa jangan menghianati Tuhan demi kepuasan nafsu dunia yang ada sebab dari padaNyalah semuanya berasal. Diberikan keberanian untuk menyatakan bahwa tidak ada seorangpun yang dapat meragukan kuasa Allah untuk berkarya di dalam dunia ini.

Memiliki modal yang dibutuhkan oleh ruang sosial memungkinkan Yesus mereproduksi tatanan sosial atau habitus yang baru bagi realitas. Hal ini berkaitan dengan apa yang disebut oleh Bourdieu sebagai kuasa simbolik. Menurut Bourdieu $^{16}$ :

"kuasa simbolik merupakan kuasa untuk mengubah dan menciptakan realitas, yakni mengubah dan menciptakannya sebagai sesuatu yang diakui, dikenali, dan juga sah. Kuasa simbolik untuk membuat orang melihat dan percaya, untuk memperkuat atau mengubah cara pandang terhadap dunia dan

\footnotetext{
${ }^{16}$ Pierre Bourdieu, Language and Symbolic Power, (Cambridge: Polity Press, 1995), p. 170
}

bagaimana mengubah dunia itu sendiri”.

Terproduksinya tatanan baru kemudian memaksa para kelompok dominan, yang juga melakukan praktik agensi, mempertahankan apa yang telah mereka produksi sebelumnya dalam habitus. Dalam kisah Yesus, hal ini terlihat dari begitu "agresifnya" para lawan Yesus (yaitu para Ahli Taurat, orang Saduki, orang Farisi) mencoba berbagai cara agar posisi mereka sebagai kelompok dominan tetap aman dan kelompok yang mereka dominasi tetap menjalankan ortodoksi yang mereka produksi.

\section{Yesus dan Praktik Pembebasan Bagi Mereka yang Didominasi}

Praktik sosial yang memiskinkan, menindas, dan mengabaikan keadilan merupakan hasil integrasi dari: habitus yang di dalamnya terjadi proses agensi internalisasi-eksternalitas dan eksternalisasi-internalitas - yang dikalikan kepemilikan modal pada ruang sosial ${ }^{17}$, dari kelompok dominan yang mengambil keuntungan. Praktik sosial inilah yang “ditantang” oleh Yesus dengan melakukan praktik sosial yang membebaskan. Dalam hal ini biasanya kelompok dominan akan cenderung mempertahankan apa yang

\footnotetext{
${ }^{17}$ Bourdieu, Pierre, Distinction: A Social Critique of the Judgement of Taste, (London: Routladge, 1996), p. 101.
} 
sudah diproduksinya. Baik Yesus dan kelompok dominan memiliki strategi tersendiri dalam usaha mempertahankan produksi sosial dan reproduksi sosial.

Para Ahli Taurat, Saduki, Farisi melukan berbagai upaya mempertahankan posisi mereka dengan mencobai dan menjebak Yesus. Namun, dalam praktiknya mereka selalu gagal melemahkan Yesus meskipun pada akhirnya mereka berhasil menghasut banyak orang termasuk Pontius Pilatus untuk menyalibkan Yesus. Hal ini terjadi karena Yesus pun memiliki strategi dalam mereproduksi sosial. Sebagai individu yang bertarung dalam ruang sosial (field), Yesus pun memiliki strategi-Nya agar praktik sosial-Nya berjalan dengan baik agar terjadi reproduksi sosial yang membebaskan dan berkeadilan. Selain memiliki modal kuasa Roh Kudus yang dilegitimasi dari Allah, Yesus pun menunjuk rekan yang adalah murid-muridNya. Murid-murid-Nya berasal dari konteks dan pergumulan yang sama sehingga menguntungkan. Keuntungan itu diperoleh salah satunya karena adanya kesamaan atau solidaritas kepentingan. ${ }^{18}$

Praktik yang dilakukan Yesus dan murid-muridnya, yang kemudian muridmurid-Nya ini memiliki modal yang sama dengan Yesus ditandai dengan pemberian kuasa dari Yesus (Lukas 9:1), bertujuan untuk menciptakan perubahan sosial dengan melawan dominasi dari para penguasa yang menindas. Dalam Injil Lukas, salah satu tujuan pekerjaan Yesus juga untuk mendominasi patriarki yang merupakan kekerasan simbolis bagi kelompok yang lain, terutama perempuan. Proses integrasi habitus dan modal serta ruang sosial dari Yesus berupaya menghilangkan penindasan dan kekerasan akibat dominasi dari kelompok-kelompok dominan tersebut.

\section{KESIMPULAN}

Dalam kerangka berpikir Bourdieu, peran Yesus dipengaruhi oleh habitus, modal, serta ruang sosialnya.Yesus sebagai individu mampu melakukan agensi agar diri-Nya bisa menjadi agen yang memengaruhi tatanan sosial atau struktur objektif yang sudah ada. Roh Kudus hadir menaungi Yesus di mana dalam ruang sosial ranah individu, modal yang dimiliki Yesus pada akhirnya dimiliki oleh para murid-Nya. Adanyasolidaritasbersama untuk melakukan upaya pembebasan bagi semua orang yang miskin, tertindas, tertawan, dan dimarginalisasi.Praktik sosial Yesus yang mereproduksi aksi sosial pada akhirnya memicu perubahan sosial sehingga mengancam kelompok yang

\footnotetext{
${ }^{18}$ Haryatmoko,Membongkar Rezim Kepastian, h. 53.
} 
mendominasi. Strategi reproduksi sosial Yesus pada akhirnya dikalahkan oleh strategi mempertahankan produksi sosial oleh kelompok dominan. Pada akhirnya perubahan sosial menunjukkan makin bertambahnya pengikut Yesus pada waktu itu.

\section{DAFTAR PUSTAKA}

Bourdieu, Pierre,Distinction: A Social Critique of the Judgement of Taste, London: Routladge, 1996. Language and Symbolic Power, Cambridge: Polity Press, 1995. ,The Rules of Art, California: Standford University Press, 1996. ,The Form of Capital, dalam J.G. Richardson (ed) Handbook of Theory and Research for the Sociology of Education, New York: Greenwood Press, 1986. Outline of a Theory of Practice, London: Cambridge University Press, 1977.

Daniel Sutoyo, "Pneumatologi Lukas: Pemberdayaan Pelayanan Kristen" dalam Antusias: Jurnal Teologi dan Pelayanan, Vol. 4, 2015.

Edwards, O.C. Jr., Injil Lukas Sebagai Cerita: Berkenalan dengan Narasi Salah Satu Injil, Jakarta: BPK Gunung Mulia, 2009.
Fitzmyer, J.A., The Gospel According to Luke (I-IX): Introduction, Translation, and Notes, New York: Doubleday \& Company, 1981.

Frank D. Macchia, "Baptism in the Holy Spirit-and-Fire: Luke's Implicitly Pneumatological Theory of Atonement, dalam Jurnal Religions, 9, 63, 2018.

Guthrie, Donald, Teologi Perjanjian Baru 2: Misi Kristus, Roh Kudus, Kehidupan Kristen, Jakarta: BPK Gunung Mulia, 2011.

Haryatmoko, Membongkar Rezim Kepastian: Pemikiran Kritis PostStrukturalis, Yogyakarta: Kanisius, 2016.

Justin Thorpe Mason, The Role of the Holy Spirit in Leading Ecclesial Change in Luke-Acts, disertasi pada The Southern Baptist Theological Seminary, Desember 2015.

Karris, Robert J., Invitation To Luke: A Commentary on the Gospel of Luke with Complete Text from The Jerusalem Bible, New York: Image Books, 1977.

Kukuh Yudha Karnanta, "Paradigma Teori Arena Produksi Kultural Sastra: Kajian Terhadap Pemikiran Pierre Bourdieu" dalam Jurnal Poetika, Vol. 1 No. 1, Juli 2013.

Yusak Tridarmanto, Hermeneutika Perjanjian Baru 1, Yogyakarta: Kanisius, 2013 